Enferm Bras 2020;19(4Supl):S1-S2

https://doi.org/10.33233/eb.v19i4.4381

\title{
EDITORIAL \\ COVID-19 e a saúde mental dos trabalhadores de saúde da atenção básica
}

\author{
Kairo Silvestre Meneses Damasceno*, Magno Conceição das Merces** \\ *Secretaria Municipal de Saúde de Salvador, Bahia, Brasil, ${ }^{* *}$ Departamento de Ciências da Vida, \\ Universidade do Estado da Bahia (UNEB), Salvador, Bahia, Brasil
}

Kairo Silvestre Meneses Damasceno: kairodamasceno@hotmail.com

Magno Conceição das Merces: mmerces@uneb.br

Em dezembro de 2019, casos inexplicáveis de pneumonia foram relatados em alguns hospitais na cidade de Wuhan, China, com histórico de exposição ao grande mercado de frutos do mar desta cidade. Foi confirmado ser uma infecção respiratória aguda causada por um novo coronavírus, cujo patógeno é o SARS-CoV-2, causador da doença COVID-19 [1,2].

A partir de então, o novo coronavírus tornou-se pandêmico devido à sua alta transmissibilidade e à disseminação assintomática, a qual dificulta a detecção para o controle através da quarentena. Isso facilita o crescimento de casos fatais em populações vulneráveis, como idosos e portadores de comorbidades, sendo agravado ainda mais pelo fato de atualmente não haver vacina ou tratamento antiviral para o novo coronavírus, cujo tratamento é sintomático, com apoio da terapia intensiva para pacientes graves [1,3,4].

No entanto, a emergência desta nova doença traz outros impactos que vão além dos casos confirmados e óbitos. Ela coloca à prova a estrutura de vigilância sanitária do país, sobretudo no atual momento de redução de investimentos em pesquisa e no Sistema Único de Saúde (SUS), que dificulta respostas ao avanço da doença bem como a detecção precoce. Assim, esta pandemia pode estabelecer a necessidade de racionar equipamentos médicos e intervenções, tendo em vista uma possível escassez de leitos hospitalares e de terapia intensiva, além de afetar a disponibilidade de mão de obra especializada, em razão dos trabalhadores de saúde estarem adoecendo, por falta de equipamentos de proteção e contato com os pacientes infectados [3-5].

Observa-se, pois, que os trabalhadores dos serviços de saúde fazem parte de um grupo de alto risco para a COVID-19, de forma que o adoecimento destes profissionais acende um alarme para a redução de recursos humanos, o que compromete o potencial de resposta à doença [3].

Este cenário estende-se à atenção básica de saúde, cuja política (Política Nacional de Atenção Básica - PNAB), aprovada no ano de 2006, abrange ações de promoção e proteção da saúde, prevenção de agravos, diagnóstico e tratamento, no âmbito individual ou coletivo, de forma a reorganizar e reorientar as práticas em saúde [6]. Os trabalhadores deste modelo de atenção à saúde estão expostos à realidade dos conflitos sociais das comunidades e ao estresse decorrente da violência nestas áreas. Além disso, convivem diretamente com o sofrimento do próximo, com a escassez de recursos e a imensa demanda de responsabilidades, que afetam a resolutividade das ações, contribuem para o desenvolvimento de doenças ligadas ao trabalho e influenciam no processo de viver humano [7-10].

Entende-se que as dificuldades e adoecimento dos trabalhadores de saúde da atenção básica podem ser exacerbados durante a epidemia da doença COVID-19 e não se restringem ao contágio pelo vírus e seus sintomas, mas também ao adoecimento mental em virtude do estresse e da carga de trabalho que a situação exige [11].

Dessa maneira, os principais motivos que levam os profissionais de saúde ao sofrimento mental durante a pandemia são: medo de ser demitido e perder seus meios de subsistência; medo de ser infectado e ser colocado em isolamento, separando-se da família; sobrecarga física e mental; filhos em casa em virtude do fechamento das escolas; necessidade de se atualizar sobre a nova doença; decisões difíceis em relação as escolhas terapêuticas; luto pelas perdas dos pacientes e colegas; estigma gerado na população com relação aos profissionais de saúde que estão em contato com portadores da COVID-19; baixa remuneração; ausência de equipamentos de proteção individual, dentre outros $[3,12,13]$. 
Portanto, cuidar da saúde mental dos trabalhadores da saúde durante a pandemia da COVID-19 é essencial para a segurança deles e dos pacientes. O gerenciamento da saúde mental, do bem-estar psicossocial e da saúde física durante esse período possibilita que os trabalhadores de saúde tenham melhor condição de desenvolver suas atividades [3].

Dentre as inúmeras estratégias de melhoria da saúde mental dos profissionais de saúde, - Ministério da Saúde recomenda, para a redução do estresse, técnicas de observação da respiração com os trabalhadores, e/ou outras Práticas Integrativas e Complementares de saúde (PICS), que possam ser testadas neste contexto [3]

\section{Referências}

1. Yuen K, Ye ZW, Fung SY, Chan CP, Jin DY. SARS-CoV-2 and COVID-19: The most important research questions. Cell Biosci 2020;10(40). https://doi.org/10.1186/s13578020-00404-4

2. Zhu N, Zhang D, Wang W, Li X, Yang B, Song J, et al. A novel coronavirus from patients with pneumonia in china. N Engl J Med 2020;382:727-33.

https://doi.org/10.1056/NEJMoa2001017

3. Brasil. Ministério da Saúde. Recomendações de proteção aos trabalhadores dos serviços de saúde no atendimento de COVID-19 e outras síndromes gripais. Secretaria de Vigilância à Saúde, 2020. Brasília: Ministério da Saúde; 2020.

4. Emanuel JE, Persad GJD, Upshur R, Thome B, Parker M, Glickman A et al. Fair allocation of scarce medical resources in the time of Covid-19. N Engl J Med 2020; 382:2049-2055. https://doi.org/10.1056/NEJMsb2005114

5. Lana RM, Coelho FC, Gomes MFC, Cruz OG, Bastos LS, Villela DAM et al. Emergência do novo coronavírus (SARS-CoV-2) e o papel de uma vigilância nacional em saúde oportuna e efetiva. Cad Saúde Pública 2020;36(3). https://doi.org/10.1590/0102-311×00019620

6. Brasil. Política Nacional de Atenção Básica. Brasília: Ministério da Saúde; 2006.

7. Camelo SH, Angerami EL. Sintomas de estresse nos trabalhadores atuantes em cinco núcleos de saúde da família. Rev Latinam Enferm 2004;12(1)14-21. https://doi.org/10.1590/S0104-11692004000100003

8. Azambuja EP, Fernandes GFM, Kerber NPC, Silveira RS, Silva ALV, Gonçalves LHT et al. Significados do trabalho no processo de viver de trabalhadoras de um programa de saúde da família. Texto Contexto Enferm 2007;16(1)71-9.

https://doi.org/10.1590/S0104-07072007000100009

9. Trindade LL, Lautert L. Síndrome de Burnout entre os trabalhadores da Estratégia de Saúde da Família. Rev Esc Enferm USP 2010;44(2):274-9. https://doi.org/10.1590/S0080-62342010000200005

10. Siqueira GF, Barrêto AJR, Menezes MS, Alves SRP, Freitas FFQ et al. Trabalho do enfermeiro na atenção primária em saúde: conhecimento dos fatores estressores. Rev Ciênc Saúde Nova Esperança 2013;11(2):72-85. [citado 2020 Abr 14]. Disponível em: http://www.facene.com.br/wp-content/uploads/2010/11/Trabalho-do-enfermeiro-na-aten\%C3\%A7\%C3\%A3o-prim\%C3\%A1ria-em-sa\%C3\%BAde.pdf

11. Silva DAR, Pimentel RFW, Merces MC. Covid-19 and the pandemic of fear: reflections on mental health. Rev Saúde Publica 2020;54:46. https://doi.org/10.11606/s15188787.2020054002486

12. FIOCRUZ. Saúde mental e atenção psicossocial na pandemia Covid-19: Orientações aos trabalhadores dos serviços de saúde. [S.I.]: Ministério da Saúde; 2020.

13. Miranda FMA, Santana LL, Pizzolato AC, Saquis LMM. Condições de trabalho e o impacto na saúde dos profissionais de enfermagem frente ao COVID-19. Cogitare Enferm 2020;25:e72702. [citado 2020 Mai 17]. Disponível em: https://revistas.ufpr.br/cogitare/article/view/72702/pdf 